\title{
The AML1-ETO fusion gene and the FLT3 length mutation collaborate in inducing acute leukemia in mice
}

\author{
Christina Schessl,1,2 Vijay P.S. Rawat, ${ }^{1,2}$ Monica Cusan, 1,2 Aniruddha Deshpande,1,2 \\ Tobias M. Kohl, ${ }^{1,2}$ Patricia M. Rosten, ${ }^{3}$ Karsten Spiekermann, ${ }^{1,2}$ R. Keith Humphries, ${ }^{3,4}$ \\ Susanne Schnittger, ${ }^{2}$ Wolfgang Kern, ${ }^{2}$ Wolfgang Hiddemann, ${ }^{1,2}$ Leticia Quintanilla-Martinez, ${ }^{5}$ \\ Stefan K. Bohlander,,$^{1,2}$ Michaela Feuring-Buske, ${ }^{1,2}$ and Christian Buske, \\ ${ }^{1}$ Clinical Cooperative Group "Leukemia," National Research Center for Environment and Health (GSF), Munich, Germany. ${ }^{2}$ Department of Medicine III, \\ Grosshadern, Ludwig Maximilians University, Munich, Germany. ${ }^{3}$ Terry Fox Laboratory, British Columbia Cancer Agency, Vancouver, British Columbia, Canada. \\ ${ }^{4}$ Department of Medicine, University of British Columbia, Vancouver, British Columbia, Canada. ${ }^{5}$ Department of Pathology, GSF, Munich, Germany.
}

The molecular characterization of leukemia has demonstrated that genetic alterations in the leukemic clone frequently fall into 2 classes, those affecting transcription factors (e.g., AML1-ETO) and mutations affecting genes involved in signal transduction (e.g., activating mutations of FLT3 and KIT). This finding has favored a model of leukemogenesis in which the collaboration of these 2 classes of genetic alterations is necessary for the malignant transformation of hematopoietic progenitor cells. The model is supported by experimental data indicating that AML1-ETO and FLT3 length mutation (FLT3-LM), 2 of the most frequent genetic alterations in AML, are both insufficient on their own to cause leukemia in animal models. Here we report that AML1-ETO collaborates with FLT3-LM in inducing acute leukemia in a murine BM transplantation model. Moreover, in a series of 135 patients with AML1-ETO-positive AML, the most frequently identified class of additional mutations affected genes involved in signal transduction pathways including FLT3-LM or mutations of KIT and NRAS. These data support the concept of oncogenic cooperation between AML1-ETO and a class of activating mutations, recurrently found in patients with $t(8 ; 21)$, and provide a rationale for therapies targeting signal transduction pathways in AML1-ETO-positive leukemias.

\section{Introduction}

The cloning of recurring chromosomal translocations and, increasingly, the molecular characterization of point mutations in patients with acute leukemia have substantially contributed to the understanding of the pathogenesis of this disease. In acute myeloid leukemia (AML), chromosomal translocations most frequently target transcription factors involved in the regulation of normal hematopoietic differentiation, whereas point mutations often affect genes involved in signal transduction pathways associated with cell proliferation (1-3). The systematic analyses of genetic alterations in patients with AML have demonstrated that genetic lesions of more than 1 transcriptional regulator, such as AML1-ETO (RUNX1MTG8), HOX fusion genes, or PML-RARA, rarely occur in the leukemic clone. Similarly, patients with concurrent mutations of FLT3, KIT, or NRAS are rare. However, there are numerous examples in which fusion genes are identified together with activating mutations of receptor tyrosine kinases, exemplified by PML-RARA and the FLT3 length mutation (FLT3-LM), which occur together in up to $35 \%$ of all patients with $\mathrm{t}(15 ; 17)$-positive AML (4).

\footnotetext{
Nonstandard abbreviations used: ALL, acute lymphoblastic leukemia; AML, acute myeloid leukemia; $\mathrm{B} 6 \mathrm{C} 3, \mathrm{C} 57 \mathrm{BL} / 6 \mathrm{~J} \times \mathrm{C} 3 \mathrm{H} / \mathrm{HeJ}$ (mice); $\mathrm{CBF}$, core-binding factor; CFU-S, colony-forming spleen unit(s); cy, cytoplasmic; ENU, $N$-ethylnitrosourea; FLT3-LM, FLT3 length mutation; GSF, National Research Center for Environment and Health; IRES, internal ribosomal entry site; KD, kinase dead; LTR, long-terminal repeat; MSCV, murine stem cell virus; PepC3, C57BL/6Ly-Pep3b $\times$ C3H/HeJ (mice); VCM, virus-containing medium; YFP, yellow fluorescent protein.

Conflict of interest: The authors have declared that no conflict of interest exists.

Citation for this article: J. Clin. Invest. 115:2159-2168 (2005).

doi:10.1172/JCI24225.
}

These observations have favored a model of pathogenesis of acute leukemia in which the 2 groups of genetic alterations, 1 affecting transcriptional regulation and hematopoietic differentiation, the other altering signal transduction cascades associated with cell proliferation, collaborate in inducing acute leukemia (5). This concept is supported by experimental data demonstrating that AML1-ETO, one of the most frequent fusion genes in AML, is not able, on its own, to induce leukemia in experimental in vivo models but requires additional mutations in yet unknown genes for induction of hematological disease. In a conditional AML1-ETO murine model, for example, only mice treated additionally with $\mathrm{N}$-ethylnitrosourea (ENU) developed AML as well as T cell lymphoblastic lymphoma, whereas untreated AML1-ETO mice showed only minimal hematopoietic abnormalities (6). Similar observations were reported from an hMRP8-AML1-ETO transgenic mouse model, which developed AML as well as T-acute lymphoblastic leukemia/lymphoma (T-ALL/ lymphoma) only after ENU mutagenesis (7), and from a murine BM transplantation model inducing constitutive expression of AML1ETO in hematopoietic progenitor cells by retroviral gene transfer (8). In a recent report, mice targeted to express AML1-ETO in the HSC compartment developed a nonlethal long-latency myeloproliferative syndrome but failed to develop acute leukemia (9).

To test the hypothesis of oncogenic cooperation between different classes of mutations, we analyzed a series of 135 patients with AML1-ETO-positive AML for the occurrence of activating mutations involving signal transduction pathways (FLT3-LM, FLT3D835, KITD816, NRAS codon 12/13/61). Because almost one-third of all AML1-ETO-positive patients had such activating mutations, we asked whether AML1-ETO would be able to collaborate with 1 of 


\section{Table 1}

Genetic alterations in patients with AML1-ETO rearrangement

\begin{tabular}{lcc} 
No. of patients & $\begin{array}{c}\text { No. of patients } \\
\text { analyzed } \\
\text { with mutation } \\
\text { detected }\end{array}$ \\
FLT3-LM & 135 & $11(8.1 \%)$ \\
FLT3D835 & 135 & $3(2.2 \%)$ \\
KITD816 & 135 & $11(8.1 \%)$ \\
NRAS codon $12 / 13 / 61$ & 135 & $13(9.6 \%)$ \\
FLT3, KIT, or NRAS mutation & 135 & $38(28.1 \%)$ \\
MLL-PTD & 87 & 0 \\
\hline
\end{tabular}

these alterations to induce leukemia. Here we demonstrated that retrovirally engineered coexpression of AML1-ETO and FLT3-LM potently synergizes to trigger the development of aggressive leukemia in a murine transplantation model.

This model will allow valuable insights into the pathogenesis of core-binding factor (CBF) leukemias and demonstrates, for the first time to our knowledge, the functional collaboration of AML1-ETO with a class of activating mutations frequently found in patients with $\mathrm{t}(8 ; 21)$-positive leukemia.

\section{Results}

AML1-ETO occurs frequently together with activating mutations involving signal transduction pathways in patients with AML. In order to characterize genetic alterations that occur together with the AML1-ETO fusion gene in AML, 135 patients with AML1-ETO (93 male, 42 female; median age 50.9, range 15.8-89.1) were screened for activating mutations in the receptor tyrosine kinases FLT3 and KIT as well as in NRAS (KITD816, NRAS codon 12/13/61). Patients included 118 with newly diagnosed AML, 4 in first relapse, and 13 classified as having therapy-related AML. Activating mutations were detected in 38 patients $(28.1 \%)$ and included mutations in the receptor tyrosine kinase FLT3 or KIT (25 patients in total) or in NRAS (13 patients). In contrast, no $M L L-P T D$ (partial tandem duplication) mutations were detected in 87 samples subjected to this analysis (Table 1). These data demonstrate that genetic alterations occurring with the AML1$E T O$ fusion gene frequently affect signal transduction pathways.

AML1-ETO cooperates with FLT3-LM in inducing acute leukemia in transplanted mice. To test the functional significance of the association of AML1-ETO with mutations involving critical signal transduction cascades, we used the murine BM transplantation model. Murine stem cell virus-based (MSCV-based) retroviral constructs carrying the AML1-ETO cDNA upstream of an internal ribosomal entry sitegreen fluorescent protein (IRES-GFP) cassette or the FLT3-LM cDNA upstream of an IRES-yellow fluorescent protein (IRES-YFP) cassette were generated to transduce and track hematopoietic cells expressing AML1-ETO $\left(\mathrm{GFP}^{+}\right)$, FLT3-LM (YFP ${ }^{+}$, or both AML1-ETO and FLT3$\mathrm{LM}\left(\mathrm{GFP}^{+} / \mathrm{YFP}^{+}\right)$in vitro and in vivo (Figure 1$)$. In order to investigate the impact of expression of AML1-ETO or FLT3-LM individually on primary primitive hematopoietic progenitor cells, we performed the colony-forming spleen assay (CFU-S). BM cells transduced with the $A M L 1-E T O / G F P$ or FLT3-LM/YFP vector or both vectors were highly purified 96 hours after the start of infection by FACS. Their ability to form spleen colonies (day 0 equivalent) was measured by transplantation of transduced cells after purification into lethally irradiated recipient mice and quantification of spleen colony formation 12 days after injection. Constitutive expression of FLT3-LM did not increase the CFU-S content compared with the GFP control. In contrast, AML1-ETO increased the CFU-S content 3.1-fold compared with the control $(P<0.002)$. Strikingly, coexpression of FLT3-LM together with AML1-ETO increased CFU-S numbers a further 2.1fold for a net increase of 6.5 -fold CFU-S compared with the control $(P<0.013)$, thus demonstrating functional collaboration of these 2 genetic alterations in enhancing the CFU-S frequency (Figure 2A). In an effort to characterize the domains responsible for the collaboration of the 2 aberrations, an FLT3-LM and an AML1-ETO mutant were generated: the FLT3-LM mutant with loss of its kinase activity (kinase dead [KD]) (FLT3-LM-KD) and the AML1-ETO mutant with an $\mathrm{L} 148 \mathrm{D}$ point mutation in the Runx1 domain of AML1-ETO (AML1-ETO-L148D), previously reported to lack DNA-binding activity. Expression of the constructs was tested by Western blot and FACS analysis, and FLT3-LM-KD was also tested for autophosphorylation as a surrogate marker for kinase activity and for its capacity to induce IL-3-independent growth in $\mathrm{Ba} / \mathrm{F} 3$ cells (Figure $1, \mathrm{~B}, \mathrm{D}, \mathrm{F}$, and $G$ ). Of note, AML1-ETO-L148D was not able to collaborate with FLT3-LM. Furthermore, the collaboration between AML1-ETO and FLT3-LM was dependent on the kinase activity of FLT3, as FLT3LM-KD did not collaborate with the fusion gene (Figure 2A). Inhibition of the kinase activity of FLT3-LM by the protein tyrosine kinase (PTK) inhibitor PKC412 was tested in a $\triangle$ CFU-S assay after 48 hours of incubation with the inhibitor. The compound induced a $62 \%$ reduction of the day 0 equivalent of the CFU-S frequency (42 versus 16 per $1 \times 10^{5}$ initiating BM cells) of cells cotransfected with FLT3-LM and $A M L 1-E T O$ compared with the untreated control, whereas the CFU-S frequency of cells infected with the GFP control vector was unchanged by the inhibitor (Figure 2B).

To further assess the potential collaboration of AML1-ETO with FLT3-LM, we carried out long-term BM transplantation studies using BM transduced with AML1-ETO or FLT3-LM alone or with both together. Over an observation period extending to 20.6 months, no disease developed in recipients of BM singly transduced with AML1-ETO $\left(3 \times 10^{5}\right.$ to $4 \times 10^{5}$ highly purified $\mathrm{GFP}^{+}$cells; $\left.n=9\right)$ or FLT3-LM $\left(7 \times 10^{4}\right.$ to $2 \times 10^{5}$ highly purified $\mathrm{YFP}^{+}$cells together with $3 \times 10^{5}$ to $1 \times 10^{6}$ nontransduced helper cells; $\left.n=9\right)$ ). To obtain mice engrafted with AML1-ETO/FLT3-LM-coexpressing BM cells, mice were injected with a mixture of $\mathrm{GFP}^{+} / \mathrm{YFP}^{+}$cells $\left(\right.$range $1 \times 10^{3}$ to $5.5 \times 10^{4}$ cells) and nontransduced normal BM cells (range $2.3 \times 10^{5}$ to $\left.1.9 \times 10^{6}\right)$. All recipients of doubly transduced BM $(n=11$ from 5 independent experiments) succumbed to an aggressive acute leukemia after a median latency time of 233 days post-transplantation (Figure 3). These mice were engrafted with GFP/YFP-coexpressing cells that were positive for AML1-ETO and FLT3-LM transcripts in the RT-PCR analysis (Figure 1C). At diagnosis the mice were moribund, cachectic, and short of breath and suffered from splenomegaly (median spleen weight $441 \mathrm{mg}$ ) (Table 2). Peripheral blood and BM contained a high proportion of blasts, and peripheral blood wbc counts were highly elevated in 5 of 11 animals (range $2 \times 10^{6}$ to $430 \times 10^{6}$ cells $/ \mathrm{ml}$ ) compared with the GFP control (range $3.5 \times 10^{6}$ to $9 \times 10^{6}$ ) (Table 2), consistent with a diagnosis of acute leukemia. Additionally, mice were anemic, with a $45 \%$ reduction in erythrocyte counts compared with the mean count in the control.

Coexpression of AML1-ETO and FLT3-LM causes both acute myeloblastic and lymphoblastic leukemia. In 7 animals the morphology of the blasts was myeloblastic (Figure 4A), whereas 4 animals were characterized by a lymphoblastic cell population (Figure 4, B and C, and Table 2). In 2 of the 7 animals with AML (mice nos. 16 and 24) the blast population was accompanied by a dominant mast cell 
A

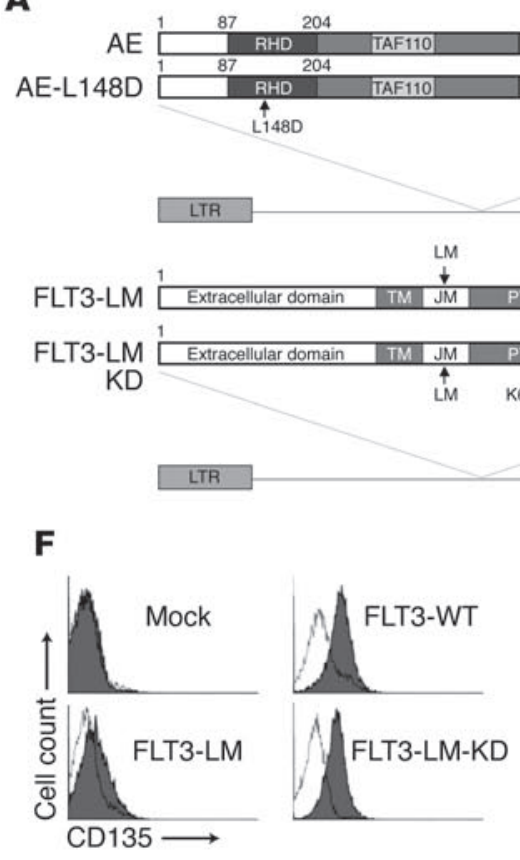

I
B

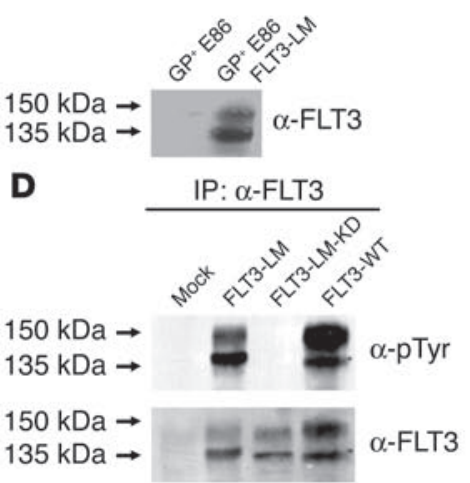

C $A E$ and $A E-L 148 D$

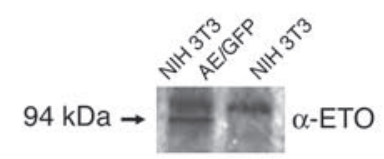

E

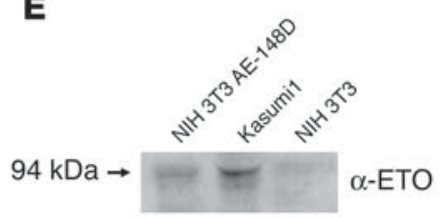

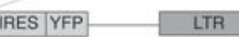

G

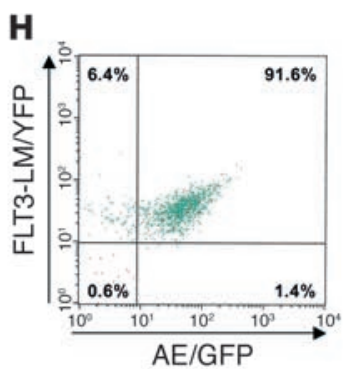

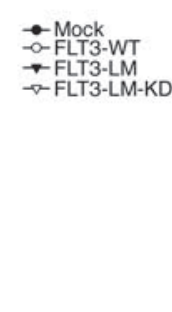

$\rightarrow \rightarrow-F L T 3-L M$ - $\rightarrow$ LLT3-KD
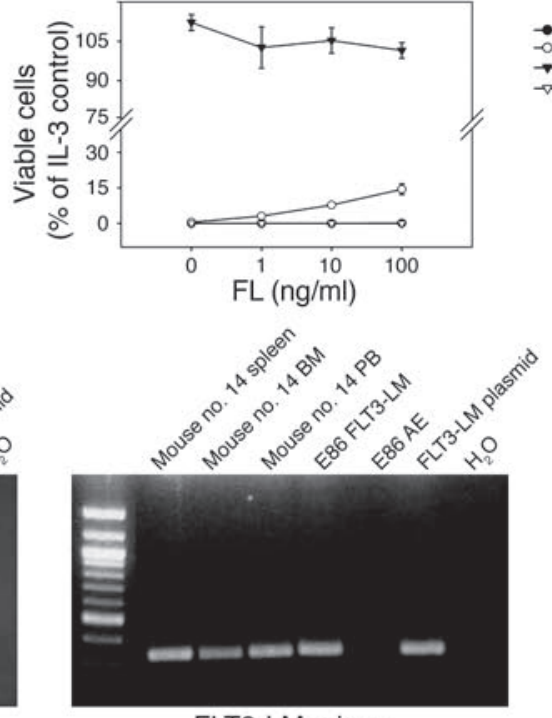

FLT3-LM primer

(2)

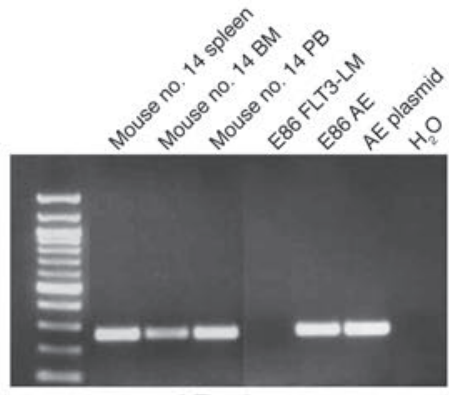

AE primer

\section{Figure 1}

Schematic diagram and analysis of expression of different constructs. (A) Retroviral constructs for expression of AML1-ETO and of the AML1-ETOL148D (31, 47), FLT3-LM, and FLT3-LM-KD mutant proteins. The GFP vector served as a control. AE, AML1-ETO; LTR, long-terminal repeat; RHD, runt homology domain; TAF110, TATA-binding protein-associated factor 110; HHR, hydrophobic heptad repeat; ZNF, zinkfinger; TM, transmembrane; JM, juxtamembrane; PTK, protein tyrosine kinase; KI, kinase insert. (B, C, and E) Western blot analysis of cellular extracts from GP+ E86 and NIH 3T3 cells transfected with the different constructs (the molecular mass is indicated). Kasumi cells served as a positive control. (D) $\alpha-p$ Tyr plot demonstrating phosphorylation of FLT3-LM and FLT3-WT but not of FLT3-LM-KD. (F) FACS analysis of Ba/F3 cells transduced with the FLT3 constructs. (G) Growth of IL-3-dependent Ba/F3 cells infected with the different constructs. (H and I) Flow cytometry and RT-PCR analysis of cells coexpressing FLT3-LM/YFP and AML1-ETO/GFP, isolated from a representative leukemic mouse. FL, FLT3 ligand; PB, peripheral blood.

population with fine metachromatic granulation in the panoptic staining (Figure 4A). The BM and spleen were infiltrated with up to $80 \%$ and $80 \%$ blasts, respectively, in the mice with AML and up to $85 \%$ and $95 \%$, respectively, in the mice suffering from ALL (Table 2 and Figures 4 and 5).

In order to determine more precisely the immunophenotype of the leukemic population, flow cytometric analyses from BM cells were performed. Seven animals suffered from AML with a Gr-1/Mac-1positive cell population in the transduced compartment, which coexpressed Sca-1 (45.2\%, range 19-73\%). Of note, in 4 of the 7 animals with AML, coexpression of CD4 was detected in $21 \%, 27 \%, 31 \%$, and $32 \%$ of BM cells (animals nos. 15, 16, 22, and 23, respectively; Table 2). Three mice suffered from B-lymphoblastic leukemia, with
$90.4 \%$ of the transduced cells expressing B220 (range 85-97\%) and lacking expression of myeloid antigens (Gr-1-positive $1.5 \%$, range 0.4-2.3\%; Mac-1-positive 1.7\%, range 1.4-1.9\%). One animal developed T cell leukemia, with coexpression of CD4 and CD8 (99\% $\mathrm{CD}^{+}, 86 \% \mathrm{CD}^{+}$in the transduced compartment) and expression of Sca- 1 in $76 \%$ of all cells (Figure 4C). Histological tissue sections and immunohistochemistry were performed in 2 diseased mice with AML, including 1 of the animals with an increase in mast cells in the peripheral blood (mouse no. 16). Both animals showed multipleorgan infiltration into hematopoietic and nonhematopoietic organs with effacement of the normal follicular architecture of the spleen (Figure 5, D and E [right side]) and an infiltration with leukemic blasts in the liver and spleen (Figure 5, A-D and F). Immunohistochemistry 
A

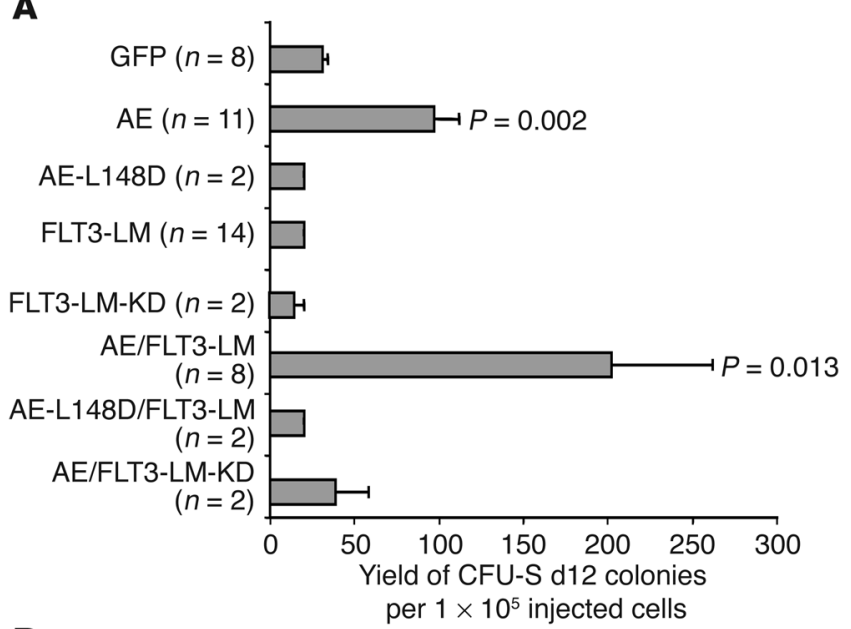

B

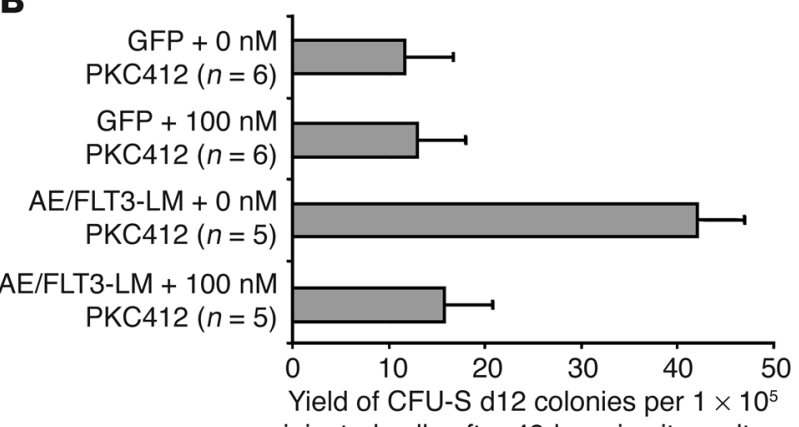

injected cells after 48-hour in vitro culture

confirmed the diagnosis of AML: blasts were positive for myeloperoxidase but showed differentiation into more mature myeloid cells with positivity for chloracetatesterase (mouse no. 14; Table 2 and Figure 5, B, C, and F). In the second mouse with AML, infiltration of organs with cells expressing mast cell-specific tryptase and CD117 could be confirmed in the primarily and secondarily transplanted mouse, indicating the presence of a malignant infiltrating mast cell population in this animal (mouse no. 16).

The leukemias were readily transplantable and had the same histomorphology within 106 days after transplantation (median survival 68 days, range 57-106 days; $n=5$ ) (Figure 3 and Figure 5, G-O). Southern blot analyses of BM from leukemic mice revealed modest numbers of proviral integrations, consistent with double infection and monoclonal or, at most, oligoclonal disease (Figure 6A). Monoclonal or oligoclonal disease is consistent with the relatively small transplant doses used but could also reflect a possible contribution of retroviral insertional mutagenesis to the transformation process. To further explore this latter possibility, 10 retroviral integration sites were subcloned and sequenced from 4 leukemic mice; all 10 sites were unique, and thus there was no indication of a common integration site associated with the leukemic transformation. Moreover, 5 sites were intergenic or not linked to known genes. The remaining sites were in introns in a $5^{\prime}$ to $3^{\prime}$ orientation most likely to lead to gene knock down rather than activation (Figure 6B and Table 3).

Since we observed coexpression of CD4 in leukemic cells of the majority of mice who developed AML in our model, we analyzed expression of CD4 and cytoplasmic (cy) CD3 in patients with AML1-ETO-positive AML; 17 of 52 patients analyzed (32.7\%) and 39 of 50 patients analyzed (78\%) were positive for $\mathrm{CD} 4$ or cyCD3,

\section{Figure 2}

Analyses of CFU-S frequencies. (A) Primary BM cells retrovirally transduced with GFP, AML1-ETO, AML1-ETO-L148D, FLT3-LM, or FLT3$L M-K D$ vectors or with combinations of the different vectors were isolated by FACS 48 hours after infection and injected into lethally irradiated mice to assess initial (day 0) CFU-S numbers. CFU-S frequency per $1 \times 10^{5}$ initiating BM cells was determined in 3 independent experiments. The number of analyzed mice and the $P$ value compared with the GFP control are indicated. (B) CFU-S frequency of primary BM cells infected with GFP or with both AML1-ETO and FLT3-LM and treated with the inhibitor PKC412 for 48 hours compared with untreated controls.

respectively. Furthermore, 31 of 52 patients (59.6\%) expressed the B cell antigen CD19, 27 of 52 patients cyCD22 (51.9\%), and 38 of 39 patients cyCD79a (97.4\%) (Figure 7). There was no difference in the extent of coexpression of lymphoid antigens in AML1-ETO-positive AML with additional activating mutations of FLT3, KIT, and NRAS $(n=14)$ versus cases without this class of mutations $(n=38)$ (data not shown). This indicates that coexpression of lymphoid and myeloid antigens in myeloblastic leukemia, which is detected in the murine model, is a common characteristic in patients with AML1-ETO-positive AML.

\section{Discussion}

The translocation $\mathrm{t}(8 ; 21)$ (q22; 22 ), which generates the AML1-ETO fusion gene, is one of the most frequent chromosomal translocations, detected in $12 \%$ of all AML patients and in up to $40 \%$ of FAB-M2 AML patients $(10,11)$. The translocation targets AML1 (RUNX1), a member of the RUNX family characterized by a DNA-binding Runt domain at the amino terminus that is retained in the fusion gene (12). This domain is necessary for DNA binding and heterodimerization of AML1 with CBFB, the non-DNA-binding subunit of the complex. As predicted by the discovery that the AML1 gene is rearranged in human hematopoietic disease, the AML1/CBFB complex was shown to be a key regulator of definitive hematopoiesis, and loss of either of these genes resulted in embryonic lethality with complete lack of definitive HSCs (13). In addition, it was recently reported that $\mathrm{AML1}^{+/-}$adult mice suffer from a 50\% reduction of long-term repopulating stem cells (14). Although it is yet not fully understood how the

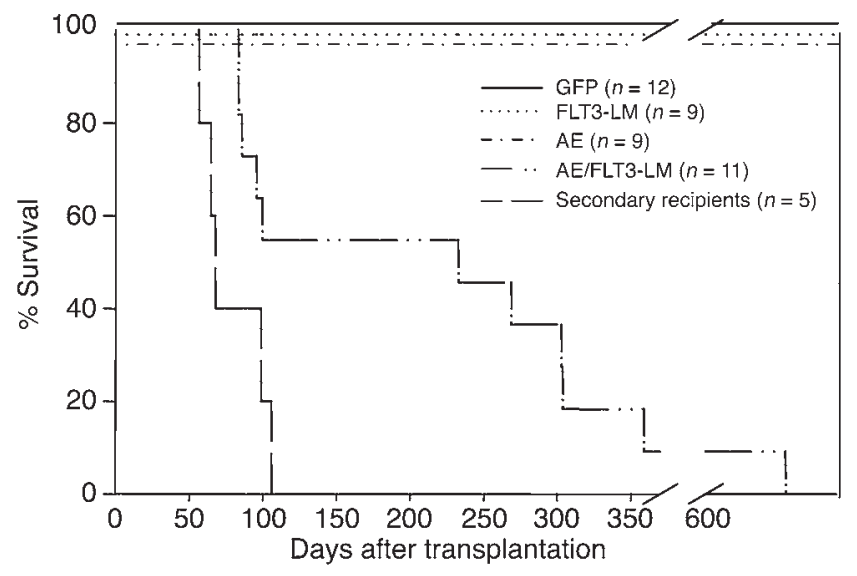

Figure 3

Survival of transplanted mice. Survival curve of mice transplanted with BM cells expressing AML1-ETO $(n=9), \operatorname{FLT3-LM~}(n=9)$, or GFP $(n=12)$, of mice transplanted with marrow cells coexpressing AML1-ETO and FLT3-LM $(n=11)$, and of secondarily transplanted mice $(n=5)$. 


\section{Table 2}

Hematological parameters of analyzed experimental mice

\begin{tabular}{|c|c|c|c|c|c|c|c|c|c|}
\hline $\begin{array}{l}\text { Mouse } \\
\text { no. }\end{array}$ & $\begin{array}{l}\text { Retroviral } \\
\text { construct }\end{array}$ & $\begin{array}{c}\text { Day of } \\
\text { sacrifice }\end{array}$ & $\begin{array}{r}\mathrm{rbc} / \mathrm{ml} \\
\times 10^{9}\end{array}$ & $\begin{array}{c}\mathrm{wbc} / \mathrm{ml} \\
\times 10^{6}\end{array}$ & $\begin{array}{l}\text { Spleen size } \\
\quad(\mathrm{mm})\end{array}$ & $\begin{array}{l}\text { Spleen weight } \\
\text { (mg) }\end{array}$ & $\begin{array}{c}\text { BM } \\
\% \text { blasts }\end{array}$ & $\begin{array}{l}\text { Spleen } \\
\text { \% blasts }\end{array}$ & $\begin{array}{c}\text { PB } \\
\% \text { blasts }\end{array}$ \\
\hline 1 & GFP & ND & 4.8 & 7.6 & ND & ND & 1 & 0 & 0 \\
\hline 2 & GFP & ND & 6.4 & 8.1 & ND & ND & 0 & 0 & 0 \\
\hline 3 & GFP & 90 & 7 & 5 & $14 \times 4$ & 51 & 2 & 0 & 0 \\
\hline 4 & GFP & ND & 5.4 & 9 & ND & ND & 0 & 0 & 0 \\
\hline 5 & GFP & 689 & 5.6 & 4.5 & $15 \times 4$ & 78 & 0 & 0 & 0 \\
\hline 6 & GFP & 721 & 7.25 & 3.5 & ND & ND & 3 & 0 & 0 \\
\hline 7 & $\mathrm{AE}$ & 444 & 6 & 13 & $13 \times 3.5$ & 63 & 8 & 0 & 0 \\
\hline 8 & $\mathrm{AE}$ & 479 & 3.1 & 15 & $14 \times 4$ & 60 & 11 & 0 & 0 \\
\hline 9 & $\mathrm{AE}$ & 493 & 5.7 & 6.9 & $14 \times 4$ & 82 & 2 & 0 & 0 \\
\hline 10 & $\mathrm{AE}$ & 615 & 5 & 7.6 & $16 \times 5$ & 117 & 14 & 0 & 0 \\
\hline 11 & FLT3-LM & 88 & 4.5 & 10 & $15 \times 4$ & 95 & 4 & ND & 0 \\
\hline 12 & FLT3-LM & ND & 4.5 & 13 & ND & ND & 2 & ND & 0 \\
\hline 13 & FLT3-LM & ND & 5.6 & 8.3 & ND & ND & 1 & ND & 0 \\
\hline $14^{\mathrm{A}}$ & AE/FLT3-LM & 233 & ND & 23 & $27 \times 7$ & 600 & 80 & 52 & 20 \\
\hline $15^{\mathrm{A}}$ & AE/FLT3-LM & 100 & 0.85 & 26.5 & $19 \times 6$ & 166 & 48 & 80 & 75 \\
\hline $16^{A}$ & AE/FLT3-LM & 612 & 1.7 & 12.5 & $14 \times 4$ & 118 & 20 & 50 & 25 \\
\hline $17^{\mathrm{B}}$ & AE/FLT3-LM & 84 & ND & 430 & $24 \times 9$ & 572 & 80 & 22 & 60 \\
\hline $18^{B}$ & AE/FLT3-LM & 84 & 4.4 & 3.3 & $21 \times 7$ & 270 & 85 & 43 & 62 \\
\hline $19^{B}$ & AE/FLT3-LM & 94 & 7.7 & 7.2 & $12 \times 4$ & ND & 85 & 20 & 95 \\
\hline $20^{B}$ & AE/FLT3-LM & 96 & 3.8 & 60 & $21 \times 6$ & 310 & 40 & 95 & 60 \\
\hline $21^{A}$ & AE/FLT3-LM & 269 & 4 & 2 & $28 \times 9$ & 650 & 38 & 62 & 30 \\
\hline $22^{\mathrm{A}}$ & AE/FLT3-LM & 303 & 2.6 & 10 & $15 \times 3$ & 200 & 24 & 76 & 38 \\
\hline $23^{A}$ & AE/FLT3-LM & 304 & 2.6 & 2.5 & $29 \times 10$ & 1,400 & 27 & 55 & 78 \\
\hline $24 \mathrm{~A}$ & AE/FLT3-LM & 359 & 2.5 & 35 & $28 \times 9$ & 760 & 39 & 77 & 64 \\
\hline
\end{tabular}

AAML; BALL. PB, peripheral blood; ND, not determined; AE, AML1-ETO.

AML1-ETO fusion gene contributes to leukemogenesis, it is thought that 1 key mechanism is the suppression of AML1- and C/EBP $\alpha$ dependent activation of genes responsible for myeloid development $(15,16)$. Perturbation of hematopoiesis by expression of AML1-ETO results in an increase in the replating capacity of murine clonogenic progenitors and in the growth of primitive human progenitor cells in vitro $(6,17)$. Furthermore, in vivo and ex vivo analyses demonstrated alterations in the differentiation pattern and proliferative capacity of murine hematopoietic cells expressing the fusion gene $(8,9,18,19)$. However, numerous murine in vivo models documented that AML1ETO on its own is not able to induce leukemia $(6,7,9,18,19)$. The observation that AML1-ETO as a single factor is nonleukemogenic is further supported by findings that nonleukemic AML1-ETOexpressing progenitor cells can be isolated from healthy individuals as well as AML patients in remission, which suggests that additional mutations in these AML1-ETO-positive progenitors are necessary for the transformation into leukemia-initiating cells (20-22). The importance of collaborating genetic events in the pathogenesis of AML1-ETO-positive leukemias has indeed been shown in different murine models, such as a conditional AML1-ETO murine model as well as an hMRP8-AML1-ETO transgenic mouse model. Only mice treated additionally with ENU developed AML or T cell lymphoma $(6,7)$. Furthermore, retrovirally expressed AML1-ETO induced myeloblastic transformation in vivo only in a background deficient in the IFN-regulatory factor IFN consensus sequence-binding protein (18). These data strongly suggest that genetic alterations cooperating with AML1-ETO play a role in inducing leukemia.

In order to characterize genetic alterations that potentially collaborate with AML1-ETO, we screened 135 patients with AML for activating mutations of signal transduction pathways or mutations affecting the MLL gene. Whereas MLL-PTD mutations, which exemplify genetic alterations involved in transcriptional regulation, were not found at all, $28 \%$ of the patients were positive for activating mutations such as FLT3-LM, FLT3D835, KITD816, or NRAS. The frequent coexistence of such mutations with AML1-ETO fits well in the model of leukemogenesis in which the collaboration of 2 classes of genetic alterations, 1 affecting transcription factors associated with hematopoietic differentiation, the other affecting signal transduction pathways associated with cell proliferation, is necessary for the malignant transformation of hematopoietic progenitor cells (3). Using the murine BM transplantation model, we obtained direct evidence for a functional collaboration of AML1-ETO with FLT3-LM in inducing leukemia, supporting the aforementioned model of leukemogenesis. Furthermore, these data demonstrate the collaboration of the 2 most frequent genetic alterations in AML, providing an important model for the understanding of both the AML1-ETO-positive and the FLT3-LM-positive leukemias.

Of note, 4 of 7 AML mice reported here expressed the T cell antigen CD4. Although the mechanisms underlying the coexpression of myeloid and lymphoid antigens in AML1-ETO-positive myeloid leukemia are not clear, one possibility is that in this AML subtype an early progenitor cell with a lineage-overlapping mixed phenotype is the target of leukemogenic transformation, as recently proposed for hematological malignancies (23). Of note, it was recently demonstrated that, in AML1-ETO-positive leukemia, evidence of lineage overlap is not restricted to the expression of cytoplasmic or surface antigens but extends to the transcriptional apparatus, since PAX5 is selectively expressed in one-third of patients with $t(8 ; 21) \mathrm{AML}$ in 
A
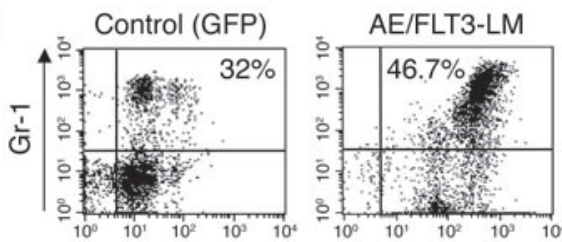

B
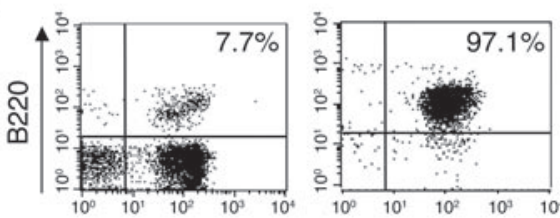

C
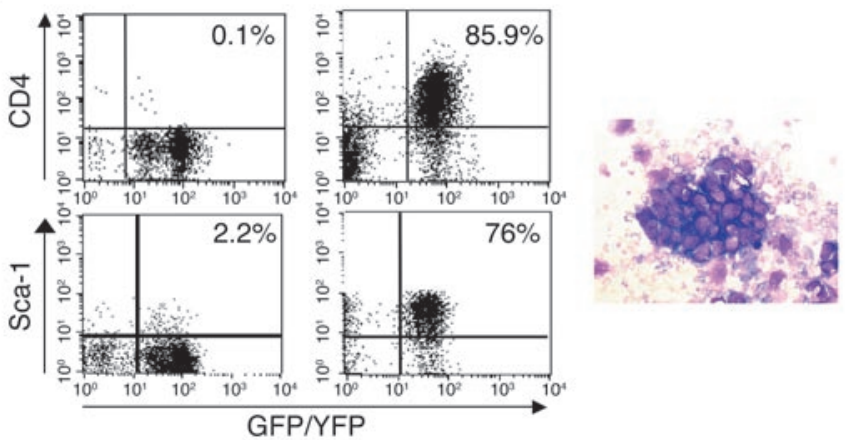

Figure 4

Immunophenotype and morphology of hematopoietic cells recovered from leukemic mice. The plots show representative FACS profiles from BM cells in comparison with cells from GFP control animals, with indication of the proportion of positive cells within the GFP+/YFP+ compartment. The photographs show cytospin preparations (H\&E; magnification, $\times 630)$ from peripheral blood (A, right image; $\mathbf{B}$ and $\mathbf{C}$ ) and from BM (A, left image). (A) AML with a dominant mast cell population (marked by arrows) (mouse no. 16). (B) B-ALL (mouse no. 17). (C) T-ALL (mouse no. 20).

contrast to all other cytogenetically defined AML subtypes (24). Furthermore, both myeloblastic and lymphoblastic leukemias of B and $T$ cell type developed in this model of AML1-ETO and FLT3-LM cooperation. This observation was also reported in other murine models: in a conditional AML1-ETO murine model, mice treated additionally with ENU developed AML as well as T cell lymphoblastic lymphoma, although most of the $\mathrm{T}$ cell neoplasms did not express the fusion gene (6). Similar observations were reported from an hMRP8-AML1ETO transgenic mouse model, which developed AML as well as T-ALL/lymphoma after ENU treatment (7). In addition, expression of AML1-ETO might contribute to the lymphoid phenotype of the leukemias in our model, as it was reported that FLT3-LM is able to induce a long-latency $\mathrm{T}$ cell lymphoma-like disease in the C57BL/ $\mathrm{C} 3 \mathrm{H}$ background (25). However, the association of FLT3-LM with a lymphoid disease seems to depend on the genetic background of the mouse strain, as FLT3-LM induced a myeloproliferative syndrome in $\mathrm{BALB} / \mathrm{c}$ mice (26). In our model, also using the $\mathrm{C} 57 \mathrm{BL} / \mathrm{C} 3 \mathrm{H}$ background, constitutive expression of FLT3-LM alone did not induce any perturbation of the hematopoietic development in vivo; this result was also recently reported in a mouse model of collaboration of FLT3-LM with MLL-SEPT6 using the C57BL/6 strain (27).

Of note, overexpression of FLT3 and activating FLT3 mutations are associated with ALL in humans, in particular in cases of ALL with hyperdiploidy or $M L L$ rearrangement, characterized by a primi- tive B cell or a mixed lymphoid-myeloid phenotype (28-30). The observations that ETV6-PDGFBR, which already by itself causes a lethal myeloproliferative syndrome in transplanted mice, induces exclusively a myeloblastic leukemia when coexpressed with AML1-ETO might point to the importance of the collaborating partner for the phenotype of the induced leukemia (31). Another possible explanation for the development of lymphoid malignancies in our model is that, in individual mice, lymphoid-committed stages of differentiation were hit by the retrovirus, resulting in lymphoblastic leukemia in these animals. This would potentially be a key difference from the human situation, in which both AML1-ETO and FLT3-LM are already present in the HSC pool $(21,32)$. An important question is whether the results were influenced by retroviral insertional mutagenesis. Most of the leukemic animals were transplanted with a low transplant dose and then suffered from monoclonal or oligoclonal disease. Although the number of retroviral integration events was low in the mice, insertional mutagenesis might have contributed to the leukemogenesis. However, analyses of the retroviral integration sites in the diseased animals showed integration into intergenic regions or introns of genes, more likely resulting in their knock down than in their activation. These data suggest that retroviral insertional mutagenesis might not play the key part in disease development, an issue that might be more accurately addressed in mouse models expressing AML1-ETO from an endogenous promoter. The long latency of the leukemias, even of secondary disease, however, strongly argues that additional secondary in vivo genetic events in the animals contributed to disease development.

To our knowledge, this is the first functional evidence of a leukemogenic collaboration of AML1-ETO with a complementary class of mutation, recurrently found in patients with $t(8 ; 21)$. It facilitates our understanding of acute leukemias associated with 2 of the most frequent genetic alterations in this disease. Furthermore, our experimental data support recent reports that show the functional relevance of activating mutations in patients with

CBF leukemias [AML1-ETO or CBFB-MYH11] by demonstrating a significantly shortened overall and event-free survival for AML1ETO-positive leukemias harboring activating mutations of FLT3 or KIT compared with those without these mutations. In contrast, RAS mutations did not affect the treatment outcome (S. Schnittger, unpublished observations) $(33,34)$. In line with these findings, it was recently shown that in patients with AML1-ETO-positive leukemia, most leukemic cells at diagnosis additionally harbored mutations in KIT, whereas in 3 patients analyzed in complete remission, only the fusion gene, but not the KIT mutation, could be detected by PCR; this strongly supports the concept of a stepwise development of disease involving 2 collaborating genetic aberrations (35). These observations encourage the systematic screening of activating mutations in patients with CBF leukemias in prospective clinical trials to evaluate more precisely their prognostic impact, and they form a rationale to consider treatment strategies targeting the signal transduction apparatus in this AML subtype.

\section{Methods}

Patient samples. BM samples from 135 adult patients with newly diagnosed AML - de novo AML $(n=118)$, secondary AML after treatment of a previous malignancy $(n=13)$, and AML at relapse $(n=4)-$ were analyzed. The diagnosis of AML was performed according to the French-American-British criteria and the WHO classification $(36,37)$. Cytomorphology, cytochemistry, cytogenetics, and molecular genetics were applied in all cases 

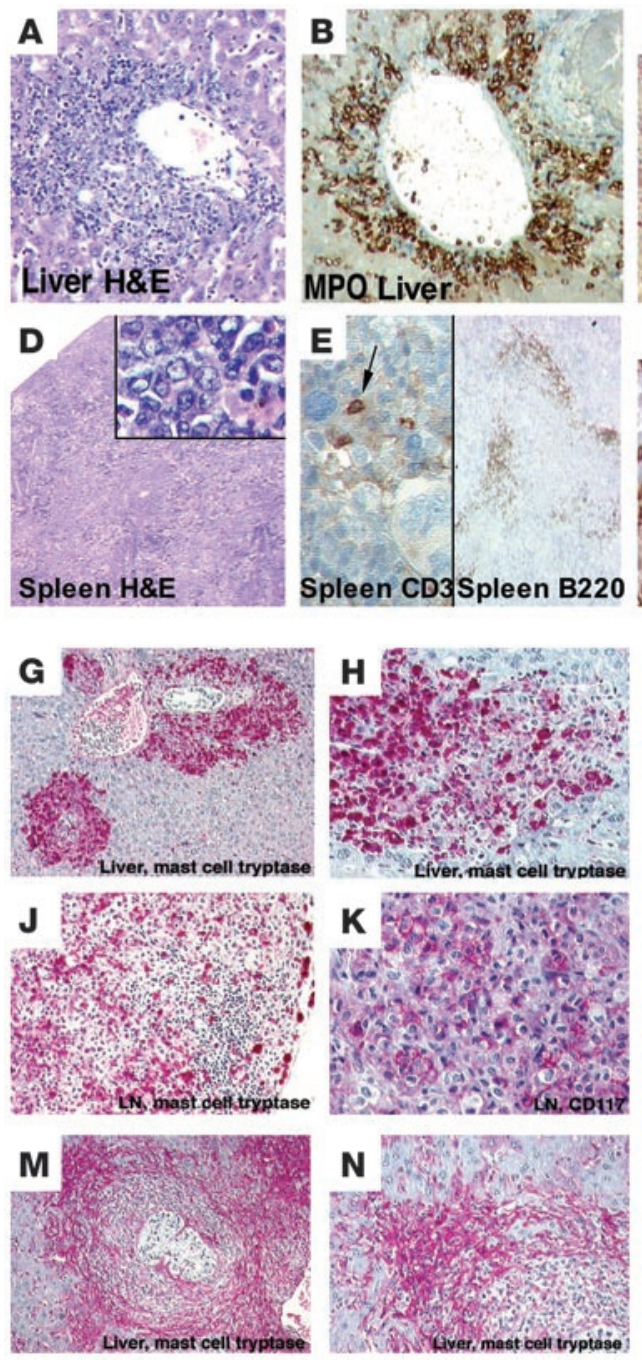
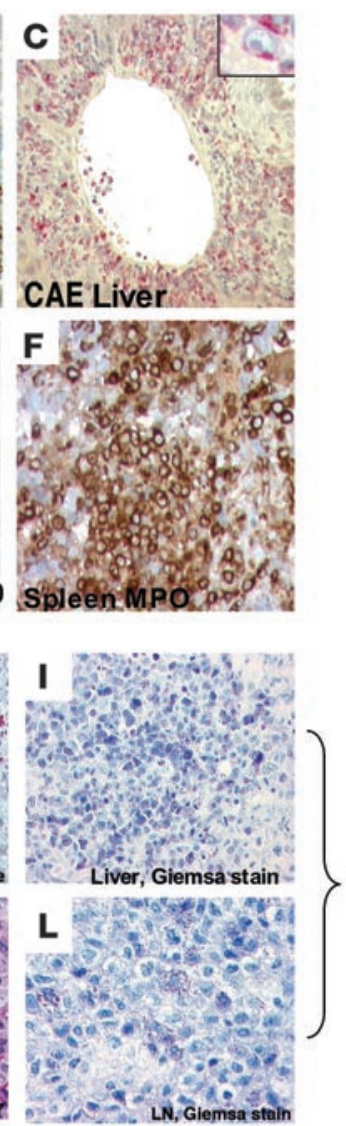

1 st recipient

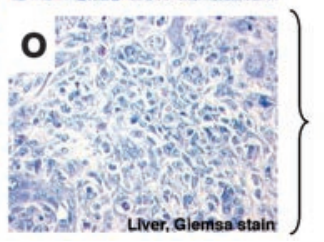

2nd recipient

\section{Figure 5}

Histological analyses of leukemic mice. (A-F) Histological analyses of AML (mouse no. 14). Original magnifications: $\mathbf{A}-\mathbf{C}, \times 200$; inset in $\mathbf{C}, \times 1,000$; $\mathbf{D}$ and right side of $\mathbf{E}, \times 250$; inset in $\mathbf{D}$, $\times 650$; left side of $\mathbf{E}, \times 400 ; \mathbf{F}, \times 400$. (G-0) Histological analyses of AML with a dominant mast cell population (mouse no. 16). (G-L) Primary recipient. (M-O) Secondary recipient. Original magnifications: $\mathbf{G}$ and $\mathbf{M}, \times 100 ; \mathbf{H}, \mathbf{J}$, and $\mathbf{N}, \times 200 ; \mathbf{I}, \mathbf{K}$, and $\mathbf{O}, \times 400 ; \mathbf{L}, \times 600$. Mast cells with metachromatic granulation in the Giemsa stain are indicated by an arrow. MPO, myeloperoxidase; CAE, $\mathrm{N}$-acetyl-chloroacetate esterase.

as described below. Both animal and human studies were approved by the Ethics Committee of Ludwig Maximilians University and abided by the tenets of the revised World Medical Association Declaration of Helsinki (http://www.wma.net/e/policy/b3.htm).

Cytogenetic and FISH analysis. Cytogenetic analyses were performed using standard techniques. For FISH, a commercially available AML1-ETO probe was used according to the manufacturer's instructions (Vysis Inc.) (38).

PCR. Molecular genetic analysis for AML1-ETO (38), MLL-PTD (39), FLT3$L M(4), N R A S$ mutations, FLT3D835, and KITD816 (40) in patient samples was performed as has been described previously (41). In leukemic mice, expression of AML1-ETO and FLT3-LM was assessed by RT-PCR in animals transplanted with BM cells coexpressing AML1-ETO/GFP and FLT3-LM/YFP. Preparation of cDNA was performed as previously described (41). For AML1-ETO the primer forward 5'-ATGACCTCAGGTTTGTCGGTCG-3' and the primer reverse
5'-TGAACTGGTTCTTGGAGCCTCCT-3' (corresponding to positions nucleotide 395 and nucleotide 633 of GenBank accession number D13979, respectively) were used; for FLT3-LM the primer forward 5'-GCAATTTAGGTATGAAAGCCAGC$3^{\prime}$ and the primer reverse $5^{\prime}$-CTTTCAGCATTTTGACGGCAACC-3' (corresponding to positions nucleotide 1,704 and nucleotide 1,920 of GenBank accession number NM_004119, respectively) were used. The annealing temperature was $57^{\circ} \mathrm{C}$. The number of PCR cycles for each gene was chosen to stop the reaction in the linear phase of amplification (35 cycles for AML-ETO and FLT3-LM). The integrity of the RNA in all samples was confirmed by $\mathrm{m} \beta-2$ microglobulin RT-PCR.

For the linker-mediated PCR (LM-PCR), integrated long-terminal repeats (LTRs) and flanking genomic sequences were amplified and then isolated using a modification of the bubble LM-PCR strategy $(42,43)$. Aliquots of the cell lysates from leukemic mice were digested with PstI or Ase (New England Biolabs Inc.), and the fragments were ligated overnight at room temperature to a double-stranded bubble linker (5'-CTCTCCCTTCTCGAATCGTAACCGTTCGTACGAGAATCGCTGTCCTCTCCTTG-3' and 5'ANTCAAGGAGAGGACGCTGTCTGTCGAAGGTAAGGAACGGACGAGAGAAGGGAGAG-3'). Next, a first PCR (PCR-A) was performed on $10 \mu \mathrm{l}$ (one-tenth) of the ligation product using a linkerspecific Vectorette primer (5'-CGAATCGTAACCGTTCGTACGAGAATCGCT-3') (Invitrogen Corp.) and an LTR-specific primer (LTR-A: 5'-CAACACACACATTGAAGCACTCAAGGCAAG- $3^{\prime}$ ) under the following conditions: 1 cycle of $94^{\circ} \mathrm{C}$ for $2 \mathrm{~min}$ utes, 20 cycles of $94^{\circ} \mathrm{C}$ for 30 seconds and $65^{\circ} \mathrm{C}$ for 1 minute, and 1 cycle of $72^{\circ} \mathrm{C}$ for 2 minutes. The bubble linker contains a 30-nucleotide nonhomologous sequence in the middle region that prevents binding of the linker primer in the absence of the minus strand generated by the LTR-specific primer. A $1-\mu l$ aliquot of the PCR-A reaction (onefifteenth) was then used as a template for a second nested PCR (PCR-B) using an internal LTR-specific primer (LTR-B: 5'-GAGAGCTCCCAGGCTCAGATCTGGTCTAAC-3') and the same linker-specific Vectorette primer as was used in PCR-A, with the following conditions: 1 cycle of $94^{\circ} \mathrm{C}$ for 2 minutes, 30 cycles of $94^{\circ} \mathrm{C}$ for 60 seconds and $72^{\circ} \mathrm{C}$ for 1 minute, and 1 cycle of $72^{\circ} \mathrm{C}$ for 2 minutes. Ten microliters (one-half) of the final PCR-B product was electrophoresed using $2 \%$ agarose tris-acetateEDTA gel. Individual bands were excised and purified using the QIAEX II Gel Extraction Kit (QIAGEN) and then cloned into PCR2.1 (Invitrogen Corp.) before sequencing of the integration site of the retrovirus.

Multiparameter flow cytometry. Immunophenotypic analyses were performed as previously described (44). The following combinations of antibodies were used: CD34/CD2/CD33, CD7/CD33/CD34, CD34/CD56/ CD33, CD11b/CD117/CD34, CD64/CD4/CD45, CD34/CD13/CD19, CD65/CD87/CD34, CD15/CD34/CD33, HLA-DR/CD33/CD34, CD4/ CD13/CD14, CD34/CD135/CD117, CD34/CD116/CD33, CD90/CD117/ CD34, CD34/NG2(7.1)/CD33, CD38/CD133/CD34, CD61/CD14/CD45, 
A

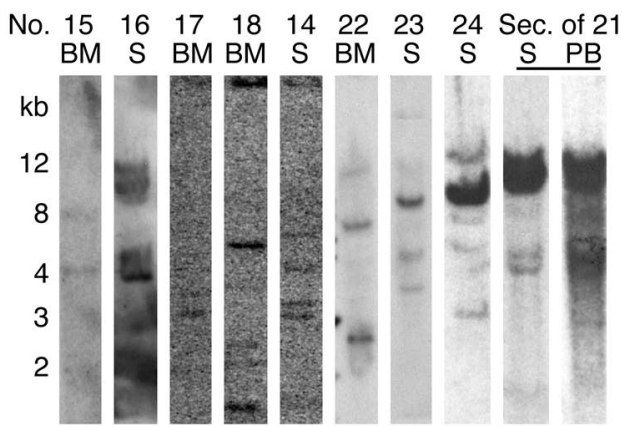

B

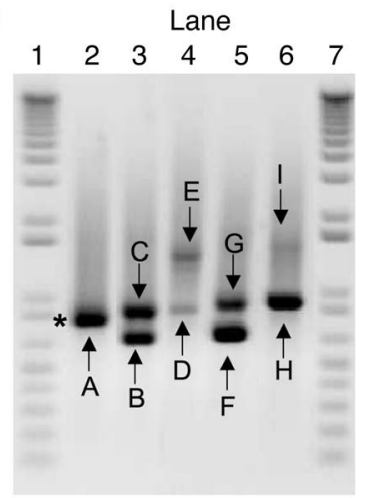

Figure 6

Analysis of proviral integrations. (A) Southern blot analysis of genomic DNA from different primary mice and a secondary recipient to detect clonal proviral integrations. DNA was digested with EcoRI, which cuts once in the proviral sequence, and blots were hybridized to a GFP/YFP probe. The mouse numbers are indicated (corresponding to those in Table 2). S, spleen; PB, peripheral blood; sec. of 21, second mouse of $1^{\circ}$ mouse no. 21. (B) Bubble PCR analyses of retroviral integration sites in diseased mice. The bands (A-I) were isolated, subcloned, and sequenced. A description of the PCR products is given in Table 3. Asterisk indicates resolution as 2 unique bands after subcloning and sequencing of integration sites.

CD36/CD235a/CD45, CD15/CD13/CD33, CD9/CD34/CD33, CD38/ CD34/CD90, CD34/CD79a/CD19, TdT/cyCD33/cyCD45, myeloperoxidase/lactoferrin/cyCD15, TdT/cyCD79a/cyCD3, and TdT/cyCD22/ cyCD3. All antibodies were purchased from Beckman Coulter Inc., except for CD64 and CD15 (Medarex Inc.), CD133 (Miltenyi Biotec), and myeloperoxidase and lactoferrin (CALTAG Laboratories). For the analysis of cytoplasmic antigens, cells were fixed and permeabilized before staining with FIX \& PERM (CALTAG Laboratories). Multiparameter flow cytometry analysis was performed with a FACSCalibur flow cytometer (BD).

The purity of all samples was $80-100 \%$. Furthermore, immunophenotyping was performed with triple staining in all cases as indicated above, testing simultaneous expression of myeloid and lymphoid antigens to exclude contaminating normal lymphoid cells.

In mice, immunophenotypic analysis of singlecell suspensions from BM, spleen, and peripheral blood was performed by flow cytometry (FACSCalibur cytometer; BD) using PE-labeled Sca-1, Gr-1, Ter-119, and CD4 antibodies and allophycocyanin-labeled Mac-1, Kit, B220, and CD8 antibodies (all from BD Biosciences - Pharmingen), as previously described (45). The surface expression of the FLT3-LM construct and the FLT3LM-KD mutant of $\mathrm{Ba} / \mathrm{F} 3$ cells was confirmed by FACS analysis (Figure 2B) using anti-human $\mathrm{CD} 135-\mathrm{PE} \mathrm{mAb}(\mathrm{BD})$ and an isotype-matched IgG1-PE control (Beckman Coulter Inc.).

cDNA constructs and retroviral vectors. For retroviral gene transfer into primary BM cells, AML1ETO cDNA was subcloned into the multiple cloning site of the modified murine stem cell virus (MSCV) 2.1 vector (41) upstream of the enhanced GFP (EGFP) gene and the internal ribosomal entry site (IRES). The FLT3-LM cDNA was subcloned into the identical MSCV vector construct carrying the enhanced YFP (Figure 1A). The MSCV vector carrying only the IRES-EGFP cassette was used as
Table 3

Identity of retroviral integration sites in diseased mice

\begin{tabular}{|c|c|c|c|c|c|}
\hline Lane $^{A}$ & $\begin{array}{c}\text { PCR } \\
\text { product }^{A}\end{array}$ & Gene & $\begin{array}{l}\text { Protein } \\
\text { family }\end{array}$ & Chromosome & $\begin{array}{c}\text { Mouse } \\
\text { no. }\end{array}$ \\
\hline \multirow[t]{2}{*}{2} & A 1 & Intergenic & & $17 q \mathrm{E} 3$ & 15 \\
\hline & A 2 & $\begin{array}{l}\text { Intron } 1 \text { of Rnf8 alias AIP37 } \\
\text { and } 5 \mathrm{kbp} 3^{\prime} \text { of Pim1 }\end{array}$ & $\begin{array}{l}\text { Ring finger } \\
\text { protein } 8\end{array}$ & $17 q A 3$ & \\
\hline \multirow[t]{2}{*}{3} & $\mathrm{~B}$ & Intergenic & & $15 q \mathrm{q} 2$ & 16 \\
\hline & C & Intron 1 of Ptp4a3 & $\begin{array}{l}\text { Protein tyrosine } \\
\text { phosphatase } 4 \text { a3 }\end{array}$ & $15 q D 3$ & \\
\hline \multirow[t]{2}{*}{4} & $\mathrm{D}$ & Hypothetical gene & & $10 q \mathrm{C} 2$ & 12 \\
\hline & $E$ & Intron 3 of GATA & $\begin{array}{l}\text { Transcription } \\
\text { factor }\end{array}$ & $6 q \mathrm{qD} 1$ & \\
\hline \multirow[t]{2}{*}{5} & $\mathrm{~F}$ & Intergenic & & $18 q D 3$ & \\
\hline & G & Intron 4 of SF3b & $\begin{array}{l}\text { Splicing factor } \\
\text { subunit b3 }\end{array}$ & $8 q \mathrm{E} 1$ & \\
\hline \multirow[t]{2}{*}{6} & $\mathrm{H}$ & $\begin{array}{l}\text { Intergenic in intron } \\
\text { of hypothetical gene }\end{array}$ & & $3 q \mathrm{~F} 1$ & 18 \\
\hline & I & $\begin{array}{l}\text { Intergenic in intron } \\
\text { of hypothetical gene }\end{array}$ & & $16 q A 1$ & \\
\hline
\end{tabular}

ALanes and PCR products according to Figure 6B. a control. The cDNA of FLT3-LM was kindly provided by D.G. Gilliland (Harvard Medical School, Boston, Massachusetts, USA) and contained a 28-amino acid duplicated sequence (CSSDNEYFYVDFREYEYDLKWEFPRENL) inserted between amino acids 610 and 611. The AML1-ETO cDNA was provided by S.W. Hiebert (Vanderbilt University School of Medicine, Nashville, Tennessee, USA).

The FLT3-LM-KD mutation K672R (a point mutation of Lys644 to Arg that disrupts an ion pair with Glu661 that is critical for nucleotide binding in FLT3-WT; ref. 46), and the L148D AML1-ETO point mutation $(31,47)$ to prevent AML1-ETO DNA binding, were generated from the full-length human FLT3-LM cDNA and the AML1-ETO cDNA, respectively, using the QuikChange Site-Directed Mutagenesis Kit (Stratagene) according to the manufacturer's instructions. The correct sequences of the constructs were confirmed by complete nucleotide sequencing, and expression was proved by Western blot and FACS analysis (Figure 1).

Cell culture. Gag-pol and envelope (GP+ E86) packaging cells, NIH 3T3 cells, and 293T cells were grown in DMEM with $10 \%$ FBS and $1 \%$ penicillin/streptomycin in a humidified incubator at $37^{\circ} \mathrm{C}$ and $5 \% \mathrm{CO}_{2}$. Primary murine $\mathrm{BM}$ cells were plated in transplant medium consisting of DMEM supplemented with $15 \%$ FBS, $1 \%$ penicillin/streptomycin, $6 \mathrm{ng} / \mathrm{ml} \mathrm{IL-3,} 10 \mathrm{ng} / \mathrm{ml} \mathrm{IL-6,} \mathrm{and} 100$ $\mathrm{ng} / \mathrm{ml} \mathrm{SCF}$ (tebu-bio GmbH). IL-3-dependent Ba/F3 cells stably expressing the empty vector alone, FLT3-WT, FLT3-LM, and FLT3-LM-KD were seeded at a concentration of $0.05 \times 10^{6}$ per milliliter in the presence or absence of IL-3 and FLT3 ligand, as described previously (48). At 72 hours, viable cells were counted in a standard hemacytometer after staining with trypan blue.

Retrovirus production. High-titer helper-free retrovirus was produced with the constructs above by individual cotransfection of each construct with Ecopac (Cell Genesys Inc.) into 293T cells using calcium chloride precipitation. The retrovirus was subsequently collected in the conditioned medium. 


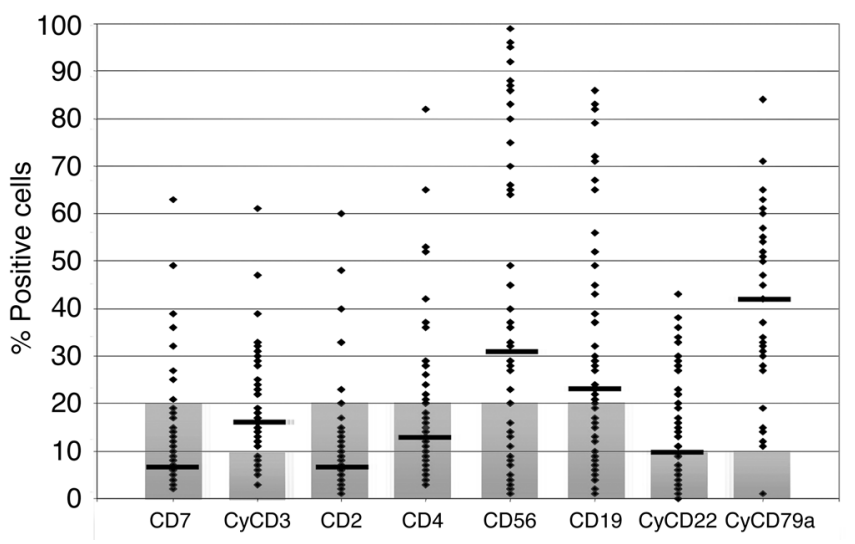

Figure 7

Expression of lymphoid antigens on 52 samples of patients with AML1ETO-positive AML, determined by immunophenotyping. Samples were defined as negative for expression of cytoplasmic antigens when less than $10 \%$ of the cells stained with the antibody, and as negative for expression of surface antigens when less than $20 \%$ of the cells stained with the antibody (shaded areas).

To optimize transduction efficiency, the virus-containing medium (VCM) of different constructs was used to transfect $\mathrm{GP}^{+} \mathrm{E} 86$ cells to establish stable packaging cell lines, or to directly infect 5-FU-mobilized BM cells in the case of FLT3-LM. Ba/F3 cells were transfected with the different constructs as previously described $(48,49)$.

Mice and retroviral infection of primary BM cells. Parental-strain mice were bred and maintained at the GSF animal facility. Donors of primary BM cells $\left[(\mathrm{C} 57 \mathrm{BL} / 6 \mathrm{Ly}-\mathrm{Pep} 3 \mathrm{~b} \times \mathrm{C} 3 \mathrm{H} / \mathrm{HeJ}) \mathrm{F}_{1}(\mathrm{PepC} 3)\right.$ mice $]$ and recipient mice $\left[(\mathrm{C} 57 \mathrm{BL} / 6 \mathrm{~J} \times \mathrm{C} 3 \mathrm{H} / \mathrm{HeJ}) \mathrm{F}_{1}(\mathrm{~B} 6 \mathrm{C} 3)\right]$ were more than 8 weeks old. Primary mouse BM cells were transduced as previously described (41). For transduction of AML1-ETO, cells were cocultured in transplant medium with AML1-ETO/GFP producer cells irradiated with 40 Gy of ${ }^{137} \mathrm{Cs}$ $\gamma$-radiation. For infection with the FLT3-LM virus, BM cells were cultured in FLT3-LM/VCM, supplemented with cytokines (IL-3, IL-6, and SCF), to achieve optimal transduction efficacy. For coinfection with the FLT3-LM and AML1-ETO retroviruses, BM cells were cultured on a mixture of $30-50 \%$ AML1-ETO/GFP and 50-70\% FLT3-LM/YFP producer cells in transplant medium or FLT3-LM/VCM supplemented with IL-3, IL-6, and SCF. Retroviral transfection of primary BM cells with the AML1-ETO mutant L148D and the FLT3-LM-KD mutant was performed as described for FLT3-LM, by cultivation of the BM in VCM supplemented with IL-3, IL-6, and SCF. All transductions were performed with the addition of $5 \mu \mathrm{g} / \mathrm{ml}$ protamine sulfate. Infected cells were highly purified (FACSVantage; BD) based on expression of GFP (for AML1-ETO alone), expression of YFP (for FLT3LM alone), or coexpression of GFP and YFP (for AML1-ETO/FLT3-LM cotransduction) before transplantation.

$B M$ transplantation and assessment of mice. FACS-purified transduced BM cells or ratios of transduced and nontransduced cells (if less than $3 \times 10^{5}$ transduced cells per recipient were available) were injected into the tail vein of 8- to 10-week-old irradiated recipient $\mathrm{F}_{1}$ (B6C3) mice (800 cGy from a ${ }^{137} \mathrm{Cs} \gamma$-radiation source). Peripheral blood or BM cell progeny of transduced cells were tracked using the GFP and/or YFP fluorescence in vivo (41). For transplantation of secondary mice, $1 \times 10^{6}$ to $2 \times 10^{6}$ cells of diseased primary animals were injected into the recipients after $800 \mathrm{cGy}$ irradiation.

$C F U$-S and $\triangle C F U$-S assay. 5-FU-mobilized primary BM cells from $\mathrm{F}_{1}$ (PepC3) donor mice were retrovirally transduced with AML1-ETO; AML1ETO-L148D; FLT3-LM; FLT3-LM-KD; both AML1-ETO and FLT3-LM; both AML1-ETO and FLT3-LM-KD; or both AML1-ETO-L148D and FLT3-LM. Cells transfected with the empty GFP vector served as control. Successfully transduced cells were isolated 48 hours after termination of infection by FACS (FACSVantage; BD). To assess initial (day 0) CFU-S numbers, purified cell populations were injected into lethally irradiated $\mathrm{F}_{1}$ (B6C3) recipient mice 96 hours after the start of infection (45). To study the effect of the selective protein tyrosine kinase inhibitor PKC412 on double-positive cells, freshly sorted cells were cultured in transplant medium with 0 and $100 \mathrm{nM}$ PKC412. After 48 hours, the cells were injected into lethally irradiated mice as described above, and the day 0 equivalent of the CFU-S frequency was calculated for both experimental groups. In this $\triangle \mathrm{CFU}-\mathrm{S}$ assay the base-line frequency of CFU-S is lower than in the CFU-S assay. The recovery of CFU-S cells was quantified by determination of the number of macroscopic colonies on the spleen at day 12 postinjection after fixation in Telleyesniczky's solution.

Southern blot. Genomic DNA was isolated from BM, spleen, and peripheral blood of diseased mice with DNAzol as recommended by the manufacturer (Invitrogen Corp.). Southern blot analysis was performed as previously described (45). DNA was digested with EcoRI and probed with a ${ }^{32} \mathrm{P}$-labeled GFP/YFP DNA. Hybridizing bands were visualized by autoradiography.

Western blot. Protein expression of AML1-ETO, AML1-ETO-L148D, FLT3LM, and FLT3-LM-KD was demonstrated by Western blotting using standard procedures (41). Membranes were probed with an anti-ETO polyclonal goat antibody and an anti-FLT3 polyclonal rabbit antibody (Santa Cruz Biotechnology Inc.). Protein expression of FLT3-LM showed 2 bands, as previously reported: in detail, the FLT3 receptor occurs in 2 different forms due to glycosylation that can be resolved in SDS-PAGE gradient gels - a 158- to $160-\mathrm{kDa}$ membrane-bound protein that is glycosylated at N-linked glycosylation sites in the extracellular domain and an unglycosylated 130to $143-\mathrm{kDa}$ protein that is not membrane bound (50-52). Phosphorylation of FLT3 was tested by Western blot using 293T cells that were starved for 12 hours at $37^{\circ} \mathrm{C}, 5 \% \mathrm{CO}_{2}$. After cell harvesting and lysis, $300 \mu \mathrm{g}$ of the lysates was immunoprecipitated with polyclonal rabbit anti-FLT3 antibody (s-18; Santa Cruz Biotechnology Inc.). Immunoprecipitates were analyzed by SDS-PAGE with mouse monoclonal anti-phosphotyrosine antibody (PY-99; Santa Cruz Biotechnology Inc.) and reprobed with anti-FLT3 antibody.

Histology. For histological analyses, sections of selected organs were prepared and stained at the Academic Pathology Laboratory, GSF (Munich, Germany), using standard protocols, as previously described (41). The mast cell-specific tryptase and the CD117 antibody were purchased from DakoCytomation. All the tumors were histopathologically classified according to the Bethesda proposals for classification on nonlymphoid and lymphoid hematopoietic neoplasms in mice $(53,54)$.

Statistical analysis. Data were evaluated using the 2-tailed Student's $t$ test for dependent or independent samples (Microsoft Excel 2002, Microsoft Corp.). Differences with $P$ values less than 0.05 were considered statistically significant.

\section{Acknowledgments}

We thank D.G. Gilliland and S.W. Hiebert for generously providing the AML1-ETO and FLT3-LM cDNA. We are grateful to T. Haferlach and C. Schoch for cytogenetic and FISH data from AML samples, to E. Wolf for careful reading of the manuscript, to B. Ksienzyk for excellent technical assistance, to T. Meyer and Novartis for PKC412, and to the members of the GSF animal facility for maintenance of the animals. This work was supported by the Deutsche Forschungsgemeinschaft (SP 556/3-1 to C. Buske and K. Spiekermann), the Deutsche Krebshilfe (70-2968-Fe I to C. Schessl and M. Feuring-Buske), and the Nationales Genomforschungsnetz-2 (WP3-SP12 to C. Buske and M. Feuring-Buske). 
Received for publication December 16, 2004, and accepted in revised form May 17, 2005.

Address correspondence to: Christian Buske, Department of Medicine III, Grosshadern, Ludwig Maximilians University, Marchionin-

1. Look, A.T. 1997. Oncogenic transcription factors in the human acute leukemias. Science. 278:1059-1064.

2. Rowley, J.D. 1999. The role of chromosome translocations in leukemogenesis. Semin. Hematol. 36:59-72.

3. Gilliland, D.G., and Tallman, M.S. 2002. Focus on acute leukemias. Cancer Cell. 1:417-420.

4. Schnittger, S., et al. 2002. Analysis of FLT3 length mutations in 1003 patients with acute myeloid leukemia: correlation to cytogenetics, FAB subtype, and prognosis in the AMLCG study and usefulness as a marker for the detection of minimal residual disease. Blood. 100:59-66.

5. Gilliland, D.G. 2002. Molecular genetics of human leukemias: new insights into therapy [review]. Semin. Hematol. 39:6-11.

6. Higuchi, M., et al. 2002. Expression of a conditional AML1-ETO oncogene bypasses embryonic lethality and establishes a murine model of human $\mathrm{t}(8 ; 21)$ acute myeloid leukemia. Cancer Cell. 1:63-74.

7. Yuan, Y., et al. 2001. AML1-ETO expression is directly involved in the development of acute myeloid leukemia in the presence of additional mutations. Proc. Natl. Acad. Sci. U. S. A. 98:10398-10403.

8. de Guzman, C.G., et al. 2002. Hematopoietic stem cell expansion and distinct myeloid developmental abnormalities in a murine model of the AML1ETO translocation. Mol. Cell. Biol. 22:5506-5517.

9. Fenske, T.S., et al. 2004. Stem cell expression of the AML1/ETO fusion protein induces a myeloproliferative disorder in mice. Proc. Natl. Acad. Sci. U. S. A 101:15184-15189.

10. Nucifora, G., et al. 1993. Detection of DNA rearrangements in the AML1 and ETO loci and of an AML1/ETO fusion mRNA in patients with $\mathrm{t}(8 ; 21)$ acute myeloid leukemia. Blood. 81:883-888.

11. Downing, J.R. 1999. The AML1-ETO chimaeric transcription factor in acute myeloid leukaemia: biology and clinical significance. Br. J. Haematol. 106:296-308

12. Peterson, L.F., and Zhang, D.E. 2004. The 8;21 translocation in leukemogenesis. Oncogene. 23:4255-4262.

13. Wang, Q., et al. 1996. Disruption of the Cbfa2 gene causes necrosis and hemorrhaging in the central nervous system and blocks definitive hematopoiesis. Proc. Natl. Acad. Sci. U. S. A. 93:3444-3449.

14. Sun, W., and Downing, J.R. 2004. Haploinsufficiency of AML1 results in a decrease in the number of LTR-HSCs, while simultaneously inducing an increase in more mature progenitors. Blood. 104:3565-3572.

15. Licht, J.D. 2001. AML1 and the AML1-ETO fusion protein in the pathogenesis of $\mathrm{t}(8 ; 21) \mathrm{AML}$. Oncogene. 20:5660-5679.

16. Pabst, T., et al. 2001. AML1-ETO downregulates the granulocytic differentiation factor C/EBPalpha in $\mathrm{t}(8 ; 21)$ myeloid leukemia. Nat. Med. 7:444-451.

17. Mulloy, J.C., et al. 2002. The AML1-ETO fusion protein promotes the expansion of human hematopoietic stem cells. Blood. 99:15-23.

18. Schwieger, M., et al. 2002. AML1-ETO inhibits maturation of multiple lymphohematopoietic lineages and induces myeloblast transformation in synergy with ICSBP deficiency. J. Exp. Med. 196:1227-1240.

19. Rhoades, K.L., et al. 2000. Analysis of the role of AML1-ETO in leukemogenesis, using an inducible transgenic mouse model. Blood. 96:2108-2115.

20. Nucifora, G., Larson, R.A., and Rowley, J.D. 1993
Persistence of the 8;21 translocation in patients with acute myeloid leukemia type M2 in long-term remission. Blood. 82:712-715.

21. Miyamoto, T., Weissman, I.L., and Akashi, K. 2000. AML1/ETO-expressing nonleukemic stem cells in acute myelogenous leukemia with 8;21 chromosomal translocation. Proc. Natl. Acad. Sci. U. S. A. 97:7521-7526.

22. Reya, T., Morrison, S.J., Clarke, M.F., and Weissman, I.L. 2001. Stem cells, cancer, and cancer stem cells. Nature. 414:105-111.

23. Miyamoto, T., et al. 2002. Myeloid or lymphoid promiscuity as a critical step in hematopoietic lineage commitment. Dev. Cell. 3:137-147.

24. Tiacci, E., et al. 2004. PAX5 expression in acute leukemias: higher B-lineage specificity than CD79a and selective association with $\mathrm{t}(8 ; 21)$-acute myelogenous leukemia. Cancer Res. 64:7399-7404.

25. Kelly, L.M., et al. 2002. PML/RARalpha and FLT3ITD induce an APL-like disease in a mouse model. Proc. Natl. Acad. Sci. U. S. A. 99:8283-8288.

26. Kelly, L.M., et al. 2002. FLT3 internal tandem duplication mutations associated with human acute myeloid leukemias induce myeloproliferative disease in a murine bone marrow transplant model. Blood. 99:310-318.

27. Ono, R., et al. 2005. Dimerization of MLL fusion proteins and FLT3 activation synergize to induce multiple-lineage leukemogenesis. J. Clin. Invest. 115:919-929. doi:10.1172/JCI200522725.

28. Armstrong, S.A., et al. 2002. MLL translocations specify a distinct gene expression profile that distinguishes a unique leukemia. Nat. Genet. 30:41-47.

29. Armstrong, S.A., et al. 2004. FLT3 mutations in childhood acute lymphoblastic leukemia. Blood. 103:3544-3546.

30. Taketani, T., et al. 2004. FLT3 mutations in the activation loop of tyrosine kinase domain are frequently found in infant ALL with MLL rearrangements and pediatric ALL with hyperdiploidy. Blood. 103:1085-1088.

31. Grisolano, J.L., O’Neal, J., Cain, J., and Tomasson, M.H. 2003. An activated receptor tyrosine kinase, TEL/PDGFbetaR, cooperates with AML1/ETO to induce acute myeloid leukemia in mice. Proc. Natl. Acad. Sci. U. S. A. 100:9506-9511.

32. Levis, M., et al. 2005. Internal tandem duplications of the FLT3 gene are present in leukemia stem cells. Blood. doi:10.1182/blood-2004-05-1902.

33. Boissel, N., et al. 2004. Incidence and prognosis of RTKs and RAS mutations in CBF AML. A retrospective study of French adult ALFA and pediatric LAME trials [abstract]. Blood. 103:2022.

34. Cairoli, R., et al. 2004. Prognostic impact of C-Kit mutations in core binding factor-leukemia [abstract]. Blood. 103:2013.

35. Wang, Y.Y., et al. 2005. AML1-ETO and C-KIT mutation/overexpression in $\mathrm{t}(8 ; 21)$ leukemia: implication in stepwise leukemogenesis and response to Gleevec. Proc. Natl. Acad. Sci. U. S. A. 102:1104-1109.

36. Bennett, J.M., et al. 1976. Proposals for the classification of the acute leukaemias. French-AmericanBritish (FAB) co-operative group. Br. J. Haematol. 33:451-458.

37. Harris, N.L., et al. 1999. World Health Organization classification of neoplastic diseases of the hematopoietic and lymphoid tissues: report of the Clinical Advisory Committee meeting. Airlie House, Virginia, November 1997. J. Clin. Oncol.
17:3835-3849.

38. Schnittger, S., et al. 2003. New score predicting for prognosis in PML-RARA+, AML1-ETO+, or CBFBMYH11+ acute myeloid leukemia based on quantification of fusion transcripts. Blood. 102:2746-2755.

39. Schnittger, S., Wormann, B., Hiddemann, W., and Griesinger, F. 1998. Partial tandem duplications of the MLL gene are detectable in peripheral blood and bone marrow of nearly all healthy donors. Blood. 92:1728-1734.

40. Spiekermann, K., et al. 2002. A new and recurrent activating length mutation in exon 20 of the FLT3 gene in acute myeloid leukemia. Blood. 100:3423-3425.

41. Rawat, V.P., et al. 2004. Ectopic expression of the homeobox gene $\mathrm{Cdx} 2$ is the transforming event in a mouse model of $\mathrm{t}(12 ; 13)(\mathrm{p} 13 ; \mathrm{q} 12)$ acute myeloid leukemia. Proc. Natl. Acad. Sci. U. S. A. 101:817-822.

42. Riley, J., et al. 1990. A novel, rapid method for the isolation of terminal sequences from yeast artificial chromosome (YAC) clones. Nucleic Acids Res. 18:2887-2890.

43. Imren, S., et al. 2004. High-level $\beta$-globin expression and preferred intragenic integration after lentiviral transduction of human cord blood stem cells. J. Clin. Invest. 114:953-962. doi:10.1172/ JCI200421838.

44. Kern, W., et al. 2004. Determination of relapse risk based on assessment of minimal residual disease during complete remission by multiparameter flow cytometry in unselected patients with acute myeloid leukemia. Blood. 104:3078-3085.

45. Pineault, N., et al. 2003. Induction of acute myeloid leukemia in mice by the human leukemia-specific fusion gene NUP98-HOXD13 in concert with Meis1. Blood. 101:4529-4538.

46. Griffith, J., et al. 2004. The structural basis for autoinhibition of FLT3 by the juxtamembrane domain. Mol. Cell. 13:169-178.

47. Lenny, N., Meyers, S., and Hiebert, S.W. 1995. Functional domains of the $\mathrm{t}(8 ; 21)$ fusion protein, AML-1/ETO. Oncogene. 11:1761-1769.

48. Spiekermann, K., et al. 2003. The protein tyrosine kinase inhibitor SU5614 inhibits FLT3 and induces growth arrest and apoptosis in AML-derived cell lines expressing a constitutively activated FLT3. Blood. 101:1494-1504.

49. Spiekermann, K., Faber, F., Voswinckel, R., and Hiddemann, W. 2002. The protein tyrosine kinase inhibitor SU5614 inhibits VEGF-induced endothelial cell sprouting and induces growth arrest and apoptosis by inhibition of c-kit in AML cells. Exp. Hematol. 30:767-773.

50. Stirewalt, D.L., and Radich, J.P. 2003. The role of FLT3 in haematopoietic malignancies. Nat. Rev. Cancer. 3:650-665.

51. Lyman, S.D., et al. 1993. Molecular cloning of a ligand for the flt $3 / \mathrm{flk}-2$ tyrosine kinase receptor: a proliferative factor for primitive hematopoietic cells. Cell. 75:1157-1167.

52. Carow, C.E., et al. 1996. Expression of the hematopoietic growth factor receptor FLT3 (STK-1/Flk2) in human leukemias. Blood. 87:1089-1096.

53. Kogan, S.C., et al. 2002. Bethesda proposals for classification of nonlymphoid hematopoietic neoplasms in mice. Blood. 100:238-245.

54. Morse, H.C., 3rd, et al. 2002. Bethesda proposals for classification of lymphoid neoplasms in mice. Blood. 100:246-258. 